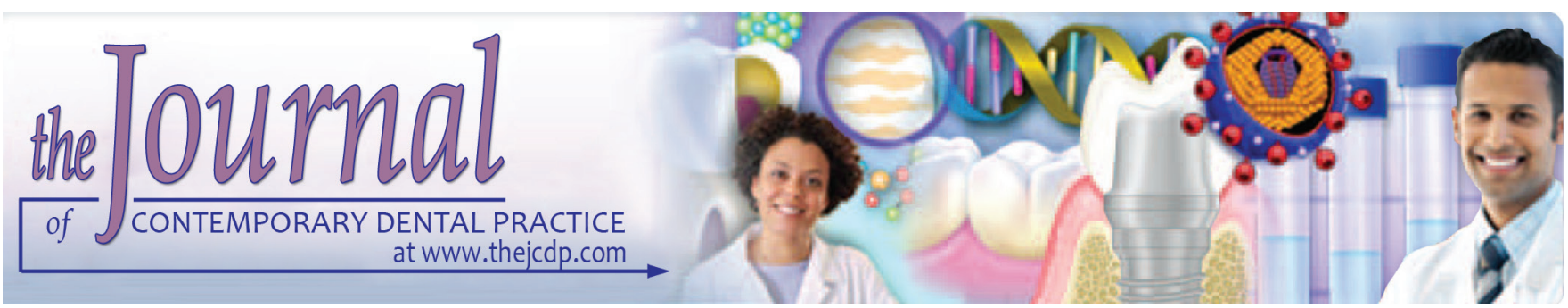

\title{
Uninfiltrated Collagen in Hybrid Layers produced after Reduced Acid-etching Time on Primary and Permanent Dentin
}

${ }^{1}$ Débora LS Scheffel, ${ }^{2}$ Cláudia Huck, ${ }^{3}$ Diana G Soares, ${ }^{4}$ Fernanda G Basso, ${ }^{5}$ Carlos A de Souza Costa
${ }^{6}$ Martha G Brackett, ${ }^{7}$ David H Pashley, ${ }^{8}$ Josimeri Hebling

\begin{abstract}
Aim: This study evaluated the influence of acid-etching time on collagen exposure in adhesive interfaces established on primary and permanent dentin.
\end{abstract}

Materials and methods: Flat dentin surfaces were produced on sound primary molars and premolars $(n=8)$. The surfaces were divided into mesial and distal halves, and each half was etched with phosphoric acid for 5 or 15 seconds. The teeth were randomly allocated into two groups according to the adhesive system applied: Prime \& Bond NT or Prime \& Bond 2.1. After the adhesive application, the specimens were processed for Goldner's trichrome staining. The thickness of the uninfiltrated collagen zone (UCZ) in the hybrid layer was measured under optical microscopy. Data were analyzed by analysis of variance and Tukey tests $(\alpha=0.05)$.

Results: The thickness of UCZ was adhesive dependent. Within the same substrate, the specimens treated with Prime \& Bond 2.1 presented thicker UCZ when etched for 15 seconds.

\footnotetext{
${ }^{1,8}$ Department of Orthodontics and Pediatric Dentistry Araraquara School of Dentistry, Universidade Estadual Paulista Araraquara, São Paulo, Brazil

${ }^{2}$ Department of Restorative Dentistry, Araraquara School of Dentistry, Universidade Estadual Paulista, Araraquara, São Paulo, Brazil

${ }^{3-5}$ Department of Physiology and Pathology, Araraquara School of Dentistry, Universidade Estadual Paulista, Araraquara, São Paulo, Brazil

${ }^{6}$ Department of Oral Rehabilitation, College of Dental Medicine Augusta University, Augusta, Georgia, USA

${ }^{7}$ Department of Oral Biology, College of Dental Medicine Augusta University, Augusta, Georgia, USA

Corresponding Author: Josimeri Hebling, Department of Orthodontics and Pediatric Dentistry, Araraquara School of Dentistry, Universidade Estadual Paulista, Araraquara, São Paulo, Brazil, Phone: +551633016334, e-mail: jhebling@foar. unesp.br
}

Collagen exposure was significantly higher for the primary teeth etched for 5 seconds and treated with Prime \& Bond 2.1.

Conclusion: The thickness of UCZ in hybrid layers is directly affected by acid-etching time and by the adhesive system applied. Primary dentin seems to be more susceptible to collagen exposure than is permanent dentin.

Clinical significance: Both acid-etching time and adhesive system can influence the amount of exposed collagen interfering on resin-dentin bond quality, especially on primary dentin.

Keywords: Collagen, Degradation, Dentin, Hybrid layer, Resin.

How to cite this article: Scheffel DLS, Huck C, Soares DG, Basso FG, de Souza Costa CA, Brackett MG, Pashley DH, Hebling J. Uninfiltrated Collagen in Hybrid Layers produced after Reduced Acid-etching Time on Primary and Permanent Dentin. J Contemp Dent Pract 2016;17(10):861-866.

Source of support: This study was supported by the São Paulo Research Foundation - FAPESP (grants 2008/02278-8 and 2009/07924-8).

\section{Conflict of interest: None}

\section{INTRODUCTION}

Resin-enamel bonds are more long-lasting and predictable than resin-dentin bonds. ${ }^{1}$ Dentin contains higher protein and water content than enamel, which, combined with structural and compositional heterogeneity, make this substrate a challenge for adhesive dentistry. ${ }^{2}$ Dentin peculiarities become increasingly evident when sound and caries-affected dentin or primary and permanent dentin are compared and can directly influence the immediate and long-term quality of resin-dentin bond. ${ }^{3-5}$

Demineralization of superficial dentin and the infiltration of solvated monomers into the collagen fibril meshwork are critical steps for the establishment of adequate adhesive interfaces. ${ }^{6}$ These steps result in a complex structure composed of the mixture of resin 
monomers and collagen fibrils, called the hybrid layer. The architecture of the hybrid layer has been considered mainly responsible for the micromechanical retention of adhesive restorations to dentin as well as for the sealing of the etched substrate. ${ }^{7}$

The establishment of a perfect hybrid layer, where water is completely displaced from demineralized dentin by the adhesive system and the exposed collagen fibrils are fully infiltrated by monomers, is not a clinical reality. The incomplete infiltration of demineralized dentin caused by the presence of excessive residual water and by the different molecular weights and hydrophilicity of resin monomers ${ }^{8,9}$ result in a zone of naked, unprotected collagen at the bottom of the hybrid layer that may be degraded by endogenous proteases over time. ${ }^{10,11}$ Resin-dentin bond aging process ultimately results in a functional failure of the hybrid layer. ${ }^{10}$

The literature suggests that primary dentin may be more sensitive to resin-dentin bond degradation than permanent dentin. The lower mineral content and differences in structure have associated primary dentin with a lower buffering capacity, what may lead to the creation of 25 to $30 \%$ thicker hybrid layers in primary dentin ${ }^{12}$ compared with permanent dentin when the substrates are etched for the same period of time. Thicker hybrid layers are more likely to contain pores and imperfections, ${ }^{13,14}$ resulting in lower bond-strength values. ${ }^{13,15}$

Demineralization of dentin by an acidic agent is time dependent, being directly influenced by the duration of the contact between acid-etching solution/gel and dentin surface. ${ }^{4}$ Increased etching time generally results in a deeper dentin demineralization and thicker hybrid layers that tend to be poorly resin infiltrated. ${ }^{13,15}$ It has been shown that primary dentin etched for about half of the time recommended for permanent dentin shows an improvement in longitudinal stability of resindentin bond, ${ }^{16}$ with no prejudice of immediate bond strength. ${ }^{5,16-18}$ Thus, it seems plausible to infer that the reduction of acid-etching time for primary dentin should decrease the depth of demineralization and the thickness of uninfiltrated collagen at the bottom of the hybrid layer and improve the quality of the adhesive interface. The aim of this study was to evaluate, through Goldner's trichrome staining ${ }^{19}$ the influence of acid-etching time of primary and permanent dentin on collagen exposure in dentin-adhesive bond. The test null hypothesis was that reduced etching time has no effect on the thickness of the uninfiltrated collagen zone (UCZ) in primary vs permanent dentin.

\section{MATERIALS AND METHODS}

Sound human premolars $(n=8)$ and primary molars $(n=8)$ were obtained from the Human Teeth Bank at the Araraquara School of Dentistry (UNESP, São Paulo, Brazil) under a protocol approved by the Institutional Ethics Committee (process \#15/08) and stored in a 0.1\% thymol solution at $4^{\circ} \mathrm{C}$. To minimize differences related to posteruptive mineralization degree, only premolars that were in function in the oral cavity for at least 3 years were included in this study.

To facilitate the handling of primary teeth with advanced root resorption, the pulp chambers were filled with low-viscosity resin (Filtek Flow, 3M ESPE, St. Paul, MN, USA) and artificial roots were created with composite resin (Z250 3M ESPE, St. Paul, MN, USA). Flat mid-coronal dentin surfaces were prepared using a 0.3-mm-thick ISOMET saw (ISOMET 1000 Buehler, Lake Bluff, IL, USA) under water cooling. Then, each surface was divided into two halves (mesial and distal) by a groove made with a 0.15 -mm-thick saw (ISOMET 1000). Each dentin half was selected and acid-etched with $35 \%$ phosphoric acid gel (Scotchbond Etchant 3M ESPE, St. Paul, MN, USA) for 5 or 15 seconds, followed by rinsing with deionized water for 10 seconds and blotted with absorbent paper in order to obtain a moist surface.

The teeth were randomly divided into two groups $(\mathrm{n}=4)$ according to the adhesive system used (Table 1), Prime \& Bond NT (Dentsply De Trey, Konstanz, Germany) or Prime \& Bond 2.1 (Dentsply Caulk, Milford, DE, USA). The adhesives were applied according to the manufacturer's instruction and light-cured for 10 seconds. Four additional layers of the adhesive systems were added and photoactivated in order to permit cutting the specimens in a microtome. The teeth were stored in water at $37^{\circ} \mathrm{C}$ for 24 hours. All procedures involving photoactivation were conducted with the same light unit, Optilux 500 (Kerr, Danbury, CT, USA), after checking the irradiance using a radiometer $\left(450 \pm 10 \mathrm{~mW} / \mathrm{cm}^{2}\right.$, Model 100, Optilux Radiometer Kerr, Danbury, CT, USA).

Table 1: Commercial name (manufacturer), classification and composition (major components) of adhesive systems

\begin{tabular}{|c|c|c|}
\hline Commercial name & Classification & Components \\
\hline $\begin{array}{l}\text { Prime \& Bond } \\
\text { NT (Dentsply De } \\
\text { Trey, Konstanz, } \\
\text { Germany) }\end{array}$ & $\begin{array}{l}\text { Total-etch } \\
\text { simplified } \\
\text { system }\end{array}$ & $\begin{array}{l}\text { Resins and di-trimethylol- } \\
\text { propane, amorphous silica, } \\
\text { PENTA (dipentaerythritol } \\
\text { penta acrylate monophos- } \\
\text { phate), photoinitiators, sta- } \\
\text { bilizers, and methylamine } \\
\text { hydrochloride acetone. }\end{array}$ \\
\hline $\begin{array}{l}\text { Prime \& Bond } 2.1 \\
\text { (Dentsply Caulk, } \\
\text { Milford, EUA) }\end{array}$ & $\begin{array}{l}\text { Total-etch } \\
\text { simplified } \\
\text { system }\end{array}$ & $\begin{array}{l}\text { Resins and trimethylolpro- } \\
\text { pane di-, PENTA, butylated } \\
\text { hydroxytoluene, 4-me- } \\
\text { thyl amino ethyl benzo- } \\
\text { ate, Photoinitiators, and } \\
\text { methylamine hydrochloride } \\
\text { acetone }\end{array}$ \\
\hline
\end{tabular}




\section{Histological Procedures}

After 24 hours in water at $37^{\circ} \mathrm{C}$, premolar roots were removed in a cutting machine (ISOMET 1000) and the teeth were sectioned to obtain two or three blocks $(2 \mathrm{~mm}$ thick $\times 2 \mathrm{~mm}$ wide $\times 5 \mathrm{~mm}$ long) per tooth, so that each block contained both halves (etched for 5 and 15 seconds). The slabs were fixed in a $10 \%$ formalin solution for 48 hours and slightly demineralized in a $10 \%$ Morse solution for 48 hours without agitation. Then, the blocks were rinsed in running tap water for 24 hours, neutralized in a 5\% sodium sulfate solution for the same period of time, and rinsed again with water for 24 hours. The specimens were dehydrated in a series of increasing ethanol solutions (70 to 100\%), cleared in xylol, and embedded in paraffin under vacuum. Approximately 5 - $\mu$ m-thick serial sections were cut from each block in a microtome (820 Spencer Microtome, American Optical Corp., Buffalo, NY, USA) and stained with Goldner's trichrome. ${ }^{19}$

\section{Optical Microscopy Analysis}

One 5- $\mu \mathrm{m}$ section from each block was randomly chosen and analyzed under $400 \times$ magnification in light microscopy (Olympus BX51 and Camedia C5060 camera, Olympus Corp, Tokyo, Japan). Using the UTHSCSA Image Tool software (University of Texas Health Science Center, San Antonio, TX, USA), five measurements of the thickness of the UCZ (red color) at the bottom of the hybrid layer were made in each section by demarcating one central and four equidistant points (two to the right and two to the left). The measurements were repeated by the same calibrated operator within a 1-week interval, and the means were calculated.

\section{Statistical Analysis}

The intraexaminer agreement for the two UCZ thickness measurements in the resin-dentin bonds was determined by an intraclass correlation coefficient (ICC). Data sets were tested by a three-way analysis of variance at three fixed criteria: Etching time (two levels), adhesive system (two levels), and type of dentin (two levels) followed by a Tukey's test. All statistical tests were considered at a significance level of $5 \%$.

\section{RESULTS}

Variations in thickness of UCZ in the hybrid layers are presented in Table 2. A high intraexaminer correlation (ICC $=0.88$ ) was obtained between the first measurement of UCZ thickness and after 7 days. Red-stained exposed collagen fibrils were identified at all resin-dentin bonds. Only the primary factors, "substrate" and "etching time," exerted a statistically significant effect on these values $(p<0.05)$. For the same type of substrate, increasing etching time from 5 to 15 seconds increased the thickness of UCZ. However, this difference was statistically significant only when Prime \& Bond 2.1 was used. Comparing the same etching time, thicker UCZ values were observed for primary dentin compared with permanent dentin, although statistical significance was verified only when the adhesive system Prime \& Bond 2.1 was applied. Thus, for this system, a greater exposure of collagen fibrils was observed in primary dentin etched for 5 seconds compared with permanent dentin etched for the same period of time. However, there was no difference in the thickness of UCZ zone between primary and permanent dentin etched for 15 seconds.

Interfaces produced by the system Prime \& Bond 2.1 are shown in Figures $1 \mathrm{~A}$ and B. Incomplete infiltration of demineralized dentin was observed in all specimens, regardless of substrate or etching time. This was evidenced by the presence of uninfiltrated collagen fibrils available for reaction with Goldner's trichrome (stained red).

\section{DISCUSSION}

Ideally, after acid-etching and adhesive application, demineralized dentin should be completely encapsulated by monomers to form a perfect hybrid layer that effectively seals dentin. However, many studies have shown that the complete infiltration of organic matrix seldom occurs, permitting the presence of naked collagen within the hybridized zone. ${ }^{3,10,20}$ These collagen fibrils have multiple matrix metalloproteinases and cathepsins strongly bound to them, which were uncovered and activated by acid-etching and can slowly degrade and solubilize the exposed dentin matrix. ${ }^{15,21}$ Additionally, after demineralization, the $48 \%$ mineral volume of dentin ${ }^{22}$ was replaced by water creating an extremely wet environment. ${ }^{23}$

Table 2: Thickness $(\mu \mathrm{m})$ of exposed collagen zone in dentin-adhesive bond produced on primary and permanent teeth vs etching time

\begin{tabular}{|c|c|c|c|c|}
\hline \multirow[b]{3}{*}{ Adhesives } & \multicolumn{4}{|c|}{ Substrate } \\
\hline & \multicolumn{2}{|c|}{ Primary dentin } & \multicolumn{2}{|c|}{ Permanent dentin } \\
\hline & 5 seconds & 15 seconds & 5 seconds & 15 seconds \\
\hline Prime \& Bond NT & $1.99(0.66)^{\star} \mathrm{A} a b$ & $2.18(0.31)^{\mathrm{A} b}$ & $1.49(0.16)^{\mathrm{A} a}$ & $2.03(0.53)^{\mathrm{A} \mathrm{ab}}$ \\
\hline Prime \& Bond 2.1 & $1.82(0.41)^{\mathrm{Ab}}$ & $2.33(0.31)^{A c}$ & $1.33(0.26)^{\mathrm{Aa}}$ & $1.96(0.39)^{A b c}$ \\
\hline
\end{tabular}

*Values represent mean (standard deviation), $n=8$. Capital letters compare vertical column data, while lowercase letters compare horizontal lines. Different letters are significant at $p<0.05$ 


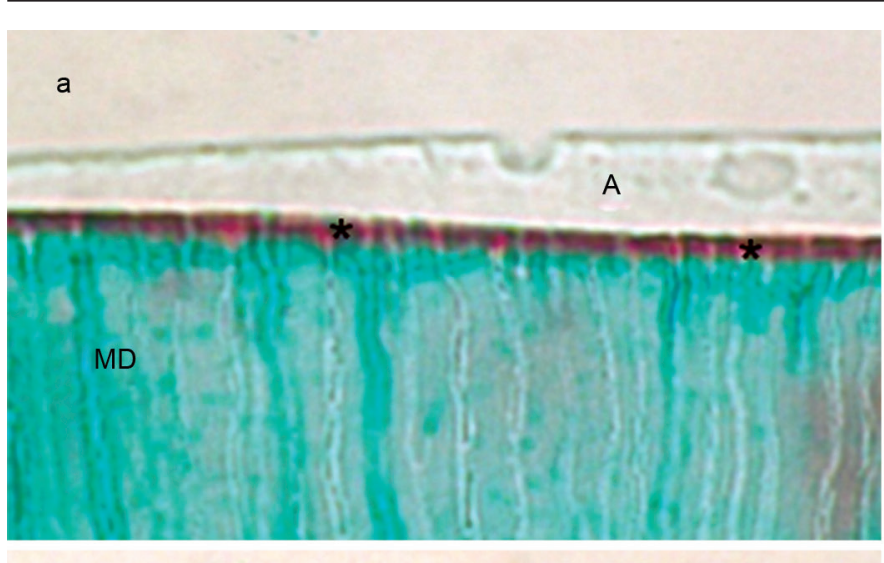

b

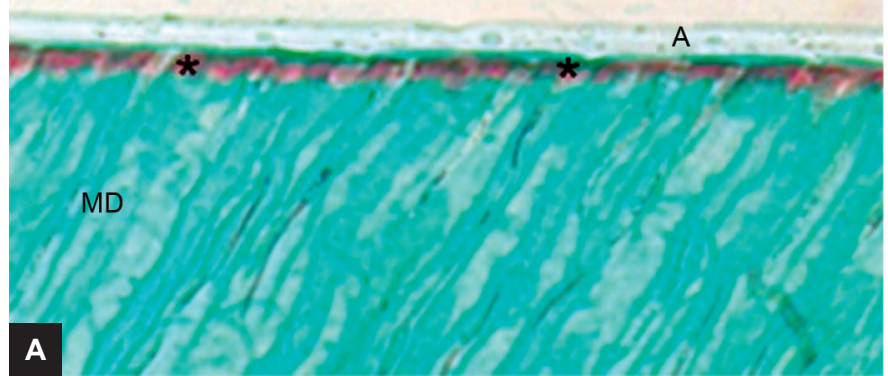

$a^{\prime}$

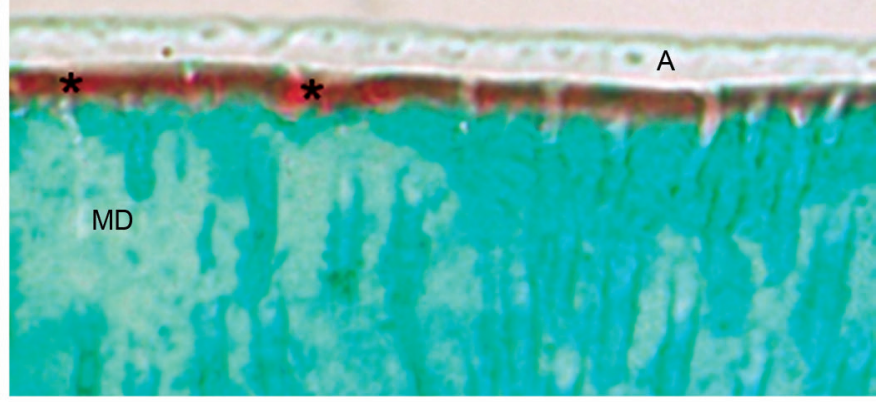

b'

Figs 1A and B: Resin-dentin bonds produced by Prime \& Bond 2.1 system applied on: (A) Primary dentin etched for 5 seconds; (a') primary dentin etched for 15 seconds; and (B) permanent dentin etched for 5 seconds, and ( $b^{\prime}$ ) permanent dentin etched for 15 seconds. A: Adhesive system; MD: Mineralized dentin (green); exposed collagen ( ${ }^{*}$ red). Goldner Trichrome 400x

Water present in etched dentin keeps collagen fibrils expanded and can be classified as free (unbound) and collagen-bound water. ${ }^{24}$ While free water represents approximately 75 to $79 \%$ of total water content in demineralized dentin, 21 to $25 \%$ is bound water. ${ }^{24}$ The application of polar solvents, such as ethanol and acetone may chemically dehydrate dentin, creating a more favorable environment for adhesive infiltration. However, Agee et $\mathrm{al}^{24}$ demonstrated that when applied for 60 seconds on dentin, ethanol and acetone remove respectively, 25 and $34 \%$ of unbound water, leaving behind most of the total water content permeating collagen fibrils. Remaining water impairs monomer infiltration and is used by proteases to degrade unprotected collagen in the hybrid layer. ${ }^{10}$

Optical microscopy coupled with Goldner's trichrome stain has been used to detect exposed collagen fibrils in resin-dentin bonds. This technique was validated by many studies ${ }^{9,14,19}$ in which the unprotected collagen fibrils were stained by the trichrome dye and turned apparent red color under light microscopy. The presence of the red coloration allows measurement of UCZ thickness at the bottom of the hybrid layer.

In the present study, a direct relationship between etching time and UCZ thickness was observed for both primary and permanent dentin, in agreement with results reported by Wang et al..$^{25}$ Those authors noted that the demineralization of permanent dentin after application of
$35 \%$ phosphoric acid for 15 seconds was two times deeper than the demineralization observed after 10 seconds. This indicates that despite the buffering capacity of dentin, ${ }^{26}$ greater dissolution of mineral phase is observed when etching time is extended, making dentin demineralization a time-dependent process.

Osorio et $\mathrm{al}^{17}$ demonstrated that rougher dentin surfaces were produced when etching time was decreased from 15 to 7 seconds, resulting in an increased surface area for interaction with the adhesive system, and consequent improvement in bond strength to dentin. This led us to test whether reducing etching time restricts dentin demineralization and enhances resin-dentin bond quality. However, Figure 1 shows that collagen fibrils still remain exposed at the base of adhesive bond even when the substrates (primary and permanent dentin) were etched for only 5 seconds. This finding suggests that the extent of dentin demineralization is not the only factor that influences monomer infiltration. Other factors, such as molecular weight, hydrophilicity of the adhesive systems, and substrate moisture may also play an important role in the process of hybrid layer stabilization. ${ }^{10}$

The composition of the adhesive system seems to be extremely influent on monomer infiltration. The results observed for Prime \& Bond NT were different from those observed for Prime \& Bond 2.1. Data collected for Prime $\&$ Bond NT require acceptance of the null test hypothesis 
that reducing etching time from 15 to 5 seconds does not change the thickness of the UCZ. However, Prime \& Bond 2.1 groups showed a higher sensitivity between depth of demineralization and monomer infiltration when acidetching time was increased.

Both Prime \& Bond NT and Prime \& Bond 2.1 use acetone as the volatile solvent. However, Prime \& Bond NT contains nanofiller particles to increase its viscosity so that it will not spread too thin and evaporates too rapidly. This system was less sensitive to etching time than Prime \& Bond 2.1. It is likely that the diffusion of adhesive monomers into the collagen network is also time dependent. ${ }^{8}$ According to the manufacturer's directions, after adhesive application and solvent evaporation, Prime \& Bond 2.1 is immediately photoactivated, while Prime \& Bond NT must remain at rest for 20 seconds on dentin surface prior to light activation. Adhesive infiltration may be more efficient when one waits a few seconds between adhesive application and photoactiovation. ${ }^{5}$ Thicker UCZ was observed for primary teeth compared with permanent teeth, which was statistically significant when the substrates were etched for 5 seconds. These results can be explained based on structural and morphological differences between the dentin of primary and permanent teeth. ${ }^{27-29}$ It has been shown that, regardless of acidetching time, primary dentin is more sensitive to acid than is permanent dentin. ${ }^{4}$ Primary dentin contains a larger number of dentinal tubules per unit area than permanent dentin ${ }^{29}$ and is more porous in the intertubular region. ${ }^{28,29}$ Since dentinal tubules are considered the preferred diffusion pathways for acid penetration in the first seconds of application, ${ }^{6}$ primary dentin demineralization may also etch faster than does permanent dentin. ${ }^{4}$ Additionally, primary dentin has lower mineral content, ${ }^{27}$ which confers greater solubility to primary dentin and a lower buffering capacity, resulting in higher demineralization when etched for the same time than permanent teeth. ${ }^{12,18}$

Reducing etching time is a clinical procedure that may minimize the discrepancy between the dentin demineralization depth and monomer infiltration, increasing the quality of resin-dentin bonds. ${ }^{13,15}$ However, there is still concern that very short etching periods are not sufficient to fully dissolve the smear layer and the underlying dentin mineral. ${ }^{14}$ It is especially relevant for permanent dentin that seems to present smear layer even after 5 seconds in contact with phosphoric acid, as observed in Figure 1. The maintenance of smear layer results in lower bond strength for permanent teeth. ${ }^{5}$ It is also important to highlight that the favorable results obtained with reduced etching times in the present study and in the literature were mainly produced on sound dentin. ${ }^{13,17}$ Therefore, further investigation should evaluate the influence of shortening etching time on caries-affected dentin, since this substrate is often used for bonding.

\section{CONCLUSION}

The depth of demineralization and the amount of uninfiltrated dentin collagen are time and adhesive dependent. In general, thicker UCZs were observed for primary teeth compared with permanent teeth.

\section{CLINICAL SIGNIFICANCE}

By reducing acid-etching time, one can decrease the depth of demineralization in order to minimize the amount of exposed collagen and increase resin-dentin bond quality and stability.

\section{REFERENCES}

1. Reis AF, Giannini M, Pereira PNR. Effects of a peripheral enamel bond on the long-term effectiveness of dentin bonding agents exposed to water in vitro. J Biomed Mater Res Part B: Appl Biomater 2008 Apr;85B(1):10-17.

2. De Munk J, Van Meerbeek B, Yoshida Y, Inoue S, Vargas M, Suzuki K, Lambrechts P, Vanherle G. Four-year water degradation of total-etch adhesives bonded to dentin. J Dent Res $2003 \mathrm{Feb} ; 82(2): 136-140$.

3. Yoshiyama M, Tay FR, Doi J, Nishitani Y, Yamada T, Itou K, Carvalho RM, Nakajima M, Pashley DH. Bonding of self-etch and total-etch adhesives to carious dentin. J Dent Res 2002 Aug;81(8):556-560.

4. Scheffel DL, Tenuta LM, Cury JA, Hebling J. Effect of acid etching time on demineralization of primary and permanent coronal dentin. Am J Dent 2012 Aug;25(4):235-238.

5. Scheffel DL, Ricci HA, de Souza Costa CA, Pashley DH, Hebling J. Effect of reducing acid etching time on bond strength to noncarious and caries-affected primary and permanent dentin. Pediatr Dent 2013;35(7):199-204.

6. Wang Y, Spencer P. Hybridization efficiency of the adhesive/dentin interface with wet bonding. J Dent Res 2003 Feb;82(2):141-145.

7. Van Meerbeek B, De Munck J, Yoshida Y, Inoue S, Vargas M, Vijay P, Van Landuyt K, Lambrechts P, Vanherle G. Buonocore memorial lecture. Adhesion to enamel and dentin: current status and future challenges. Oper Dent 2003 May-Jun;28(3): 215-235.

8. Eliades G, Vougiouklakis G, Palaghias G. Heterogeneous distribution of single bottle adhesive monomers in the resindentin interdiffusion zone. Dent Mater 2001 Jul;17(4):277-283.

9. Spencer P, Wang Y, Walker MP, Wieliczka DM, Swafford JR. Interfacial chemistry of the dentin/adhesive bond. J Dent Res 2000 Jul;79(7):1458-1463.

10. Tjäderhane L, Nascimento FD, Breschi L, Mazzoni A, Tersariol IL, Geraldeli S, Tezvergil-Mutluay A, Carrilho MR, Carvalho RM, Tay FR, et al. Optimizing dentin bond durability: control of collagen degradation by matrix metalloproteinases and cysteine cathepsins. Dent Mater 2013 Jan;29(1): 116-135.

11. Marghalani HY, Bakhsh T,Sadr A, TagamiJ. Ultramorphological assessment of dentin-resin interface after use of simplified adhesives. Oper Dent 2015 Jan-Feb;40(1):E28-E39.

12. Nör JE, Feigal RJ, Dennison JB, Edwards CA. Dentin bonding: SEM comparison of the resin-dentin interface in primary and permanent teeth. J Dent Res 1996 Jun;75(6):1396-1403. 
13. Pioch $\mathrm{T}$, Stotz $\mathrm{S}$, Buff E, Duschner H, Staehle HJ. Influence of different etching times on hybrid layer formation and tensile bond strength. Am J Dent 1998 Oct;11(5):202-206.

14. Wieliczka DM, Kruger MB, Spencer P. Raman imaging of dental adhesive diffusion. Appl Spectrosc 1997 Nov;51(11):1593-1596.

15. Hashimoto M, Ohno H, Endo K, Kaga M, Sano H, Oguchi H. The effect of hybrid layer thickness on bond strength: demineralized dentin zone of the hybrid layer. Dent Mater 2000 Nov;16(6):406-411.

16. Sanabe ME, Kantovitz KR, de Souza Costa CA, Hebling J. Effect of acid etching time on the degradation of resin-dentin bonds in primary teeth. Am J Dent 2009 Feb;22(1):37-42.

17. Osorio R, Aguilera FS, Otero PR, Romero M, Osorio E, Garcia-Godoy F, Toledano M. Primary dentin etching time, bond strength and ultra-structure characterization of dentin surfaces. J Dent 2010 Mar;38(3):222-231.

18. Sardella TN, Castro FLA, Sanabe ME, Hebling J. Shortening of primary dentin etching time and its implication on bond strength. J Dent 2005 May;33(5):355-362.

19. Spencer $P$, Wang $Y$, Katz JL. Identification of collagen encapsulation at the dentin/adhesive interface. J Adhes Dent 2004 Summer;6(2):91-95.

20. Tjäderhane L, Nascimento FD, Breschi L, Mazzoni A, Tersariol ILS, Geraldeli S, Tezvergil-Mutluay A, Carrilho M, Carvalho RM, Tay FR, et al. Strategies to prevent hydrolytic degradation of the hybrid layer: a review. Dent Mater 2013 Oct;29(10):999-1011.

21. Carrilho MR, Tay FR, Donnelly AM, Agee KA, Tjäderhane L, Mazzoni A, Breschi L, Foulger S, Pashley DH. Host-derived loss of dentin matrix stiffness associated with solubilization of collagen. J Biomed Mater Res Part B: Appl Biomater 2009 Jul;90(1):373-380.

22. Nakabayashi N, Pashley DH. Hybridization of dental hard tissues. Chicago (IL): Quintessence Publishing; 1998. p. 37-56.

23. Grégoire G, Sharrock P, Delanné M, Delisle M-B. Depletion of water molecules during ethanol wet-bonding with etch-andrinse dental adhesives. Mater Sci Eng C Mater Biol Appl 2013 Jan 1;33(1):21-27.

24. Agee KA, Prakki A, Abu-Haimed T, Naguib GH, Nawareg MA, Tezvergil-Mutluay A, Scheffel DL, Chen C, Jang SS, Hwang H, et al. Water distribution in dentin matrices: bound vs. unbound water. Dent Mater 2015 Mar;31(3):205-216.

25. Wang Y, Spencer P, Hager C, Bohaty B. Comparison of interfacial characteristics of adhesive bonding to superficial versus deep dentin using SEM and staining techniques. J Dent 2006 Jan;34(1):26-34.

26. Camps J, Pashley DH. Buffering action of human dentin in vitro. J Adhes Dent 2000 Spring;2(1):39-50.

27. Angker L, Nockolds C, Swain MV, Kilpatrick N. Quantitative analysis of the mineral content of sound and carious primary dentin using BSE imaging. Arch Oral Biol 2004 Feb;49(2): 99-107.

28. Hirayama M, Yamada M, Miake K. An electron microscope study on dentinal tubules of human deciduous teeth. Shikwa Gakuho 1986 Jun;86(6):1021-1031.

29. Sumikawa DA, Marshall GW, Gee L, Marshall SJ. Microstructure of primary tooth dentin. Pediatr Dent 1999 Nov-Dec;21(7):439-444. 